\title{
Resolving a Challenge in the Modeling of Hydrogen Production Using Steam Reforming of Methane in Monolith Reactors Using CFD Methods
}

\author{
Mohammad Irani \\ Research Institute of Petroleum Industry (RIPI), Tehran, Iran \\ Email: iranim@ripi.ir
}

Received 2012

\begin{abstract}
Reaction modeling of SMR (Steam Methane Reforming) process inside monolith reactors using two approaches were investigated and compared with each other. In the first approach, the reactions were assumed to take place exactly on the wall surfaces, while in the second approach they considered inside a thin thickness near the walls. Experiments of SMR were carried out in a lab-scale monolith reactor. A single-channel was considered and CFD model were developed for each of aforementioned approaches. Comparisons between modeling results and experimental data showed that the first approach (surface model) gives better results. Performing reactions are difficult and expensive, CFD simulations are considered as numerical experiments in many cases. It was concluded that obtained results from CFD analysis gives precise guidelines for further studies on optimization of SMR monolithic reactor performance.
\end{abstract}

Keywords: Hydrogen Production; Monolithic Reactor; CFD; SMR; Surface-model; Volume-model

\section{Introduction}

Hydrogen is one of the cleanest fuels which can be used instead of fossil fuels. There are variety of applications for hydrogen in industries such as: fuel cells, green cars, metal production and fabrication, Petroleum recovery and refinery, chemical processing, power generation, etc. The mentioned applications made the Hydrogen a strategic product. The most famous process for hydrogen production is Steam Reforming of Methane (SMR) which converts Methane and other hydrocarbons presented in natural gas into Hydrogen in large centralized industrial plants. Researchers are being done in order to develop small-scale SMR technologies to enable the development of distributed hydrogen production and delivery infrastructure [1,2]. Therefore due to attaining this goal small-scale SMR technologies should be modeled and optimized [3-7]. Monolith catalysts can be widely used in many applications particularly for their high geometric surface area, low pressure drop and good mechanical strength and durability [8]. In addition using monolithic reactors have significant advantages such as reduced capital cost, smaller footprints and potentially easier transportation [1, 9-11]. These advantages can be particularly valuable when considering the exploration of remote resources such as offshore reserves of natural gas[12]. In the present work, hydrogen production in a bench-scale SMR monolith reactor was studied. Two different approaches were presented in the literature for implementing reaction rates in monolith reactor models, namely surface approach and volumetric approach. In the first approach, the diffusion into the thin catalytic layers (washcoat) in modeling of monolithic reactors is neglected and the reactions are assumed to take place at the surface of the washcoat. Case studies for this approach include steam Methane reforming
(SMR) [14], steam reforming of methanol [15-17], ethanol steam reforming [18] and autothermal reforming of n-hexadecane [19]. Hartmann et al. [20,21] studied Hydrogen production by catalytic partial oxidation of iso-octane at varying flow rate and fuel/oxygen ratio.

Massing et al. [24] studied the catalytic conversion of propene and demonstrated that diffusional limitations within the washcoat limit the propene conversion. Stutz and Poulikakos [25] considered diffusion and reaction inside the washcoat of a monolithic reformer.

In the present study, the surface and volumetric approaches were used to model SMR in a single-channel monolith reactor. The obtained results from each model were compared with experimental data.

\section{Mathematical Model}

In order to model the problem, five sets of equations should be solved; continuity equation, momentum balance, energy and species transport equations.

$$
\begin{gathered}
\nabla \cdot(\rho v)=0 \\
\nabla \cdot(\rho v v)=-\nabla P+\nabla \cdot\left[\mu\left(\nabla v+\nabla v^{T}\right)\right]+\rho g+S \\
\nabla \cdot(v(\rho H+P))+\nabla \cdot\left(\sum_{i=1}^{n} h_{i} J_{i}\right)=-\nabla \cdot(q)+S_{R}
\end{gathered}
$$

where, $\rho$ represents mixture density, $\mathrm{v}$ is velocity vector, $\mu$ is the mixture viscosity, $\mathrm{H}$ and hi are total enthalpy and enthalpy of species, respectively and $C_{i}$ stands for concentration of chemical species. $\mathrm{P}$ is the static pressure and $\mathrm{S}_{\mathrm{R}}$ is the heat of reaction. 
Fluent 6.2.16 CFD software was used and an axi-symmetric model was employed for each of the two approaches.

\subsection{Approach (I): Surface-based Reaction Rate}

In this model, it was assumed that the reactions take place at the reactor walls. This model ignores the effect of washcoat thickness, porosity and diffusion in pores because of the small thickness of washcoat. The reaction rate can be multiplied by loading of the catalyst, Fwashcoat, to give the surface based reaction rate $\left(\mathrm{s}_{\mathrm{i}}\right)$ that is implemented in the CFD code:

$$
S_{i}=r_{i} \times \mathrm{F}_{\text {washcoat }}[=] \frac{\mathrm{kgmol}}{\mathrm{kgcat} . \mathrm{s}} \times \frac{\mathrm{kg} \mathrm{cat}}{\mathrm{m}^{2}}=\frac{\mathrm{kgmol}}{\mathrm{m}^{2} . \mathrm{s}}
$$

The value of measured Fwashcoat was $0.04 \mathrm{~kg} / \mathrm{m}^{2}$. The surface based catalytic reaction is used as source term in right hand of species continuity equation (equation 4).

\subsection{Approach (II): Volume-based Reaction Rate}

In this model, the reactions were assumed to take place in a porous zone of catalyst with $0.07 \mathrm{~mm}$ thickness.

Diffusive mass flux in the porous zone was calculated using the following equation:

$$
J_{i}=-\rho \frac{W_{i}}{W} D_{M, e f f, i} \nabla X_{i}
$$

Here $D_{M, e f f e, i}$ is the equivalent Fick's diffusion coefficient which includes two terms: $D_{K n u d, i}$ and $D_{M, i}$ :

$$
\frac{1}{D_{M, e f f, i}}=\frac{\tau}{\varepsilon}\left(\frac{1}{D_{M, i}}+\frac{1}{D_{k d u d, i}}\right)
$$

$D_{M, i}$ and $D_{\text {Knud }, i}$ are mixture diffusion and Knudsen diffusion coefficients. Also R is the gas constant, $\varepsilon$ porosity, T the gas temperature and $\tau$ is tortuosity that represents the deviation of the washcoat pore length from the ideal cylinder [26,27]. In order to describe catalytic reaction rate in $\mathrm{kmol} / \mathrm{m3}$.s, the surface exposed to reaction per unit volume of washcoat should be calculated:

$$
P_{\text {washcoat }}=\frac{\text { surface exposed to reaction }}{\text { washcoat volume }}=\frac{2 \pi r_{\text {in }} h}{\pi \times h \times\left(r_{\text {out }}^{2}-r_{\text {in }}^{2}\right)}
$$

Here, rin is inner diameter and rout the outer diameter of washcoat and $\mathrm{h}$ is the monolith's height. By multiplying $P_{\text {washcoat }}$ by $S_{i}$, the reaction rate based on catalyst volume, $V_{i}$ is obtained:

$$
V_{i}=S_{i} \times P_{\text {washcoat }}[=] \frac{\mathrm{kmol}}{\mathrm{m}^{2} . \mathrm{s}} \times \frac{\mathrm{m}^{2}}{\mathrm{~m}^{3}}=\frac{\mathrm{kmol}}{\mathrm{m}^{3} . \mathrm{s}}
$$

This term is used as reaction source in equation (4) for approach II.

\subsection{The Kinetic Models Describing the Catalytic Reactions}

The reaction rates of SMR on Ni catalyst reported by Froment $[29,30]$ are adopted in this study. The species which exist as reactant and products in SMR consist of: $\mathrm{CO}, \mathrm{H} 2, \mathrm{CO}, \mathrm{CO} 2$, $\mathrm{H} 2 \mathrm{O}$ and $\mathrm{CH} 4$.

\section{Results and Discussion}

The predicted distribution of the products and reactants along the reactor using approach (I) is given in Figure 1.

The figure shows exponential changes in the mass fractions of reactants and products along the reactor. In addition, almost $95 \%$ of the changes occur at a distance of $9 \mathrm{~mm}$ from the entrance.

The contour plots of Hydrogen mole fraction inside the reactor is given in Figure 2.

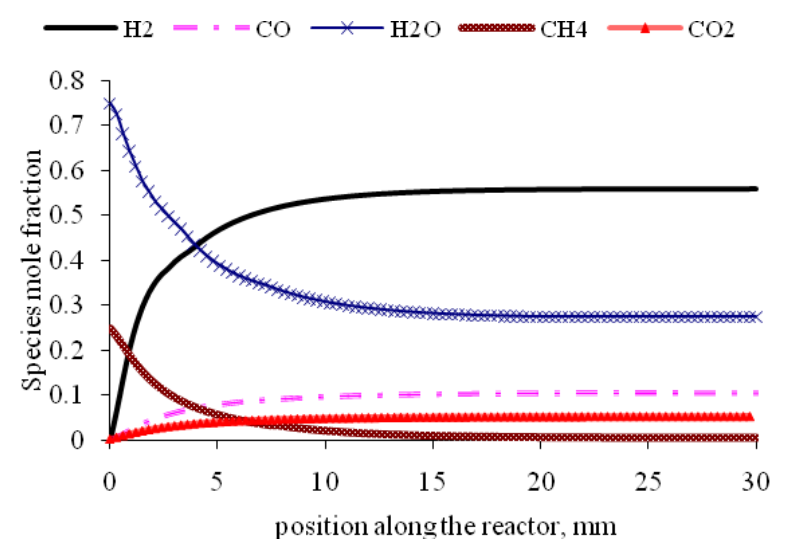

Figure 1. Distribution of $\mathrm{H} 2, \mathrm{CH} 4, \mathrm{CO}, \mathrm{H} 2 \mathrm{O}$ along the reactor (Model- I). 
Higher concentrations of Hydrogen are observed near the reactor walls where it is produced. However, the radial gradient of hydrogen concentration is descended along the reactor due to convectional and diffusional mass transfer and lower rate of Hydrogen production in the frontier regions. Figures $\mathbf{3}$ and $\mathbf{4}$ reveal that the main changes in the concentrations of reactants and products occur in the first $9 \mathrm{~mm}$ of the reactor. The predicted distribution of the products and reactants along the reactor using approach (II) is given in Figure 8.

This figure shows that there are considerable changes in the concentrations at the reactor output. Radial distribution of hydrogen plotted in Figure 9 confirms this point by showing that there is still a significant difference between the concentrations in the lengths of 25 and $30 \mathrm{~mm}$. The product gas species from experiments were measured by GC. A comparison between experimental and predicted values of Methane conversion at different reactor temperatures is given in Figure 6. This figure shows that the predicted conversions of approach (I) at all the examined temperatures are more accurate than that of approach (II).

It can be explained by the fact that due to low diffusion coefficient in the washcoat, the species can only diffuse to a limited thickness of the washcoat. Therefore, the available volume of the porous zone for chemical reactions is smaller than the total volume of washcoat. Thus the conversions of the reactions are underestimated in this model. In the other hand, by considering the fact that the residence time of gas species inside the reactor is in the order of milliseconds [10], it can be realized that the species don't have enough opportunity to diffuse into the porous

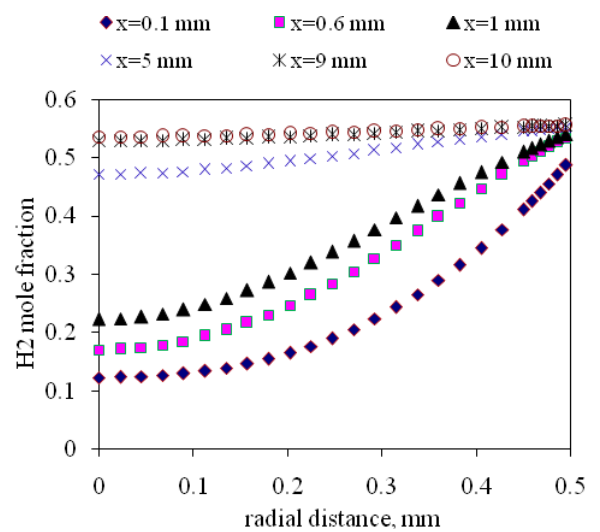

Figure 3. $\mathrm{H}_{2}$ mole fraction at 6 locations (Model- I).

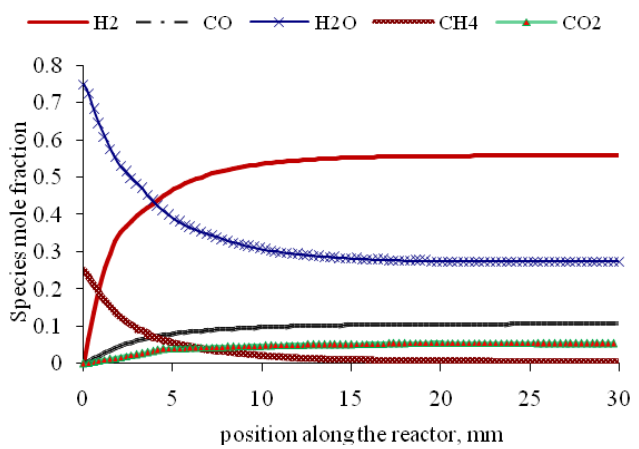

Figure 4. Distribution of $\mathrm{H} 2, \mathrm{CH} 4, \mathrm{CO}, \mathrm{H} 2 \mathrm{O}$ along the reactor (Model- II). washcoat.

The comparison of predicted and experimental values of Hydrogen yield (Figure 7) shows similar results and the predictions of approach (I) are better than that of approach (II) for all examined reactor temperatures.

The experimental and predicted values of Hydrogen selectivity are compared in Table $\mathbf{1}$. The values in this table show that the error values for approach (I) are less than 5\%, while for approach (II) it is more than $30 \%$. The whole above discussion testify that predictions of approach (I) is more accurate than that of approach (II).

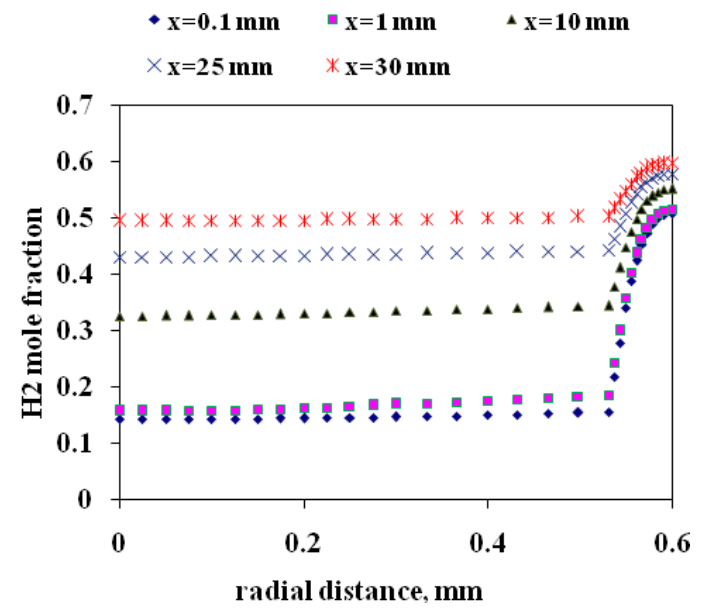

Figure 5. $\mathrm{H}_{2}$ mole fraction at 6 locations (Model- I).

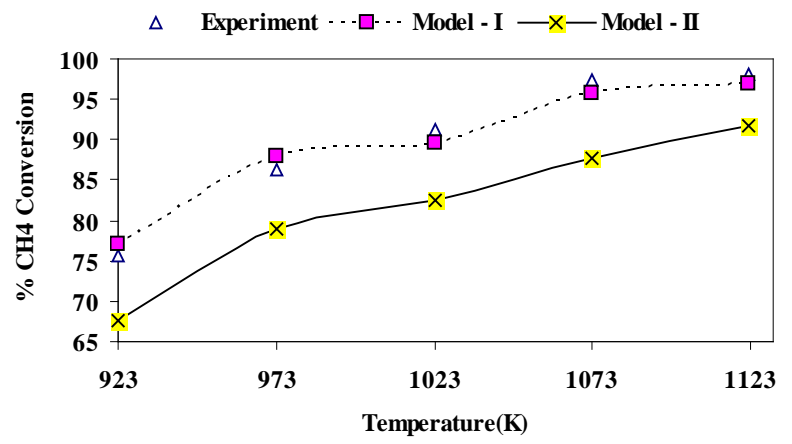

Figure 6. Comparison of $\mathrm{CH}_{4}$ conversions between Model-1, Model-2 and experiments.

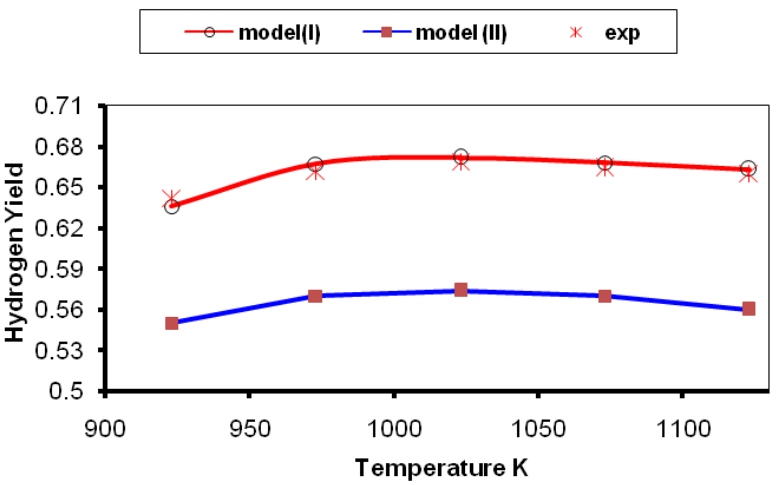

Figure 7. Comparison of $\mathrm{H}_{2}$ yield between Model-I, Model-II and experiments. 
Table 1. Comparisons between the two models and experimental results.

\begin{tabular}{cccccc}
\hline & Model 1 & Model 2 & Exp & $\begin{array}{c}\text { Model 1 } \\
\text { Error (\%) }\end{array}$ & $\begin{array}{c}\text { Model 2 } \\
\text { Error (\%) }\end{array}$ \\
\hline $\begin{array}{c}\mathrm{H}_{2} \text { selectivity* } \\
\left(\mathrm{T}=700^{\circ} \mathrm{C}\right)\end{array}$ & 71.26 & 51.83 & 73.78 & 3.41 & 29.7 \\
$\begin{array}{c}\mathrm{H}_{2} \text { selectivity } \\
\left(\mathrm{T}=750^{\circ} \mathrm{C}\right)\end{array}$ & 75.65 & 55.37 & 77.81 & 2.775 & 28.8 \\
$\begin{array}{c}\mathrm{H}_{2} \text { selectivity } \\
\left(\mathrm{T}=800^{\circ} \mathrm{C}\right)\end{array}$ & 78.1 & 58.36 & 79.11 & 1.27 & 26.2 \\
\hline
\end{tabular}

\section{Conclusion}

The current study presents two approaches for numerical modeling and implementation of reaction rates in simulation of heat and mass transfer in monolithic reactors. The chemical conversion on the Ni-catalyst is modeled using general kinetic models for SMR and Water-Gas-Shift (WGS) reaction rates based on Langmuir-Hinshelwood type. Monolithic reactor was simulated using mentioned two approaches under steady-state condition. The results of two approaches were compared to corresponding experimental data and a comprehensive evaluation was carried out. The results showed that the predictions of surface-based approach are more accurate than that of volume-based approach. The volume-based model underestimates the conversion of reactions. Small values of effective diffusion coefficient in porous washcoat layer and low residence time are the main reasons of discrepancy between volume-based approach and experiment results. In total, despite of its ease of implementation, the first approach (surface reactions) gives better results both in generality and accuracy. Also. It was concluded that obtained results from CFD analysis gives precise guidelines for further studies on optimization of SMR monolithic reactor performance.

\section{REFERENCES}

[1] A.Y. Tonkovich , S. Perry, Y. Wang, D. Qiu, T. LaPlante and W.A. Rogers, "Microchanel process technology for compact Methane steam reforming," Chem. Eng .Sci , vol. 59, pp. 4819-4824, 2004.

[2] D. Hickman and L.D. Schmidt, “ Production of syngas by direct catalytic oxidation of Methane”, Science , vol. 259, pp. 343-346,1993.

[3] E.E. Gonzo, “ Hydrogen from methanol-steam reforming. Isothermal and adiabatic monolith reactors' simulation.” ,Int J Hydrogen Energy, vol.33,pp. 3511 - 3516, 2008.

[4] E. Lo'pez, A. Irigoyen, T. Trifonov, A. Rodri'guez, J. Llorca, “ A million-channel reformer on a fingertip: Moving down the scale in hydrogen production”, Int.J. Hydrogen Energy, vol.35 ,pp. $3472-3479,2010$.

[5] L. Shi, “ Bayless D J and Prudich M E. A CFD model of autothermal reforming”, Int J Hydrogen Energy ,vol .35 ,pp. 3472 $3479,2010$.

[6] W. Cai, F. Wang, A.V. Veen, C. Descorme, Y. Schuurman and W. Shen, " Mirodatos C. Hydrogen production from ethanol steam reforming in a micro-channel reactor”, Int J Hydrogen Energy, vol. 35,pp. 1152 - 1159, 2010.

[7] X. Zhai, S. Ding, Y. Cheng, Y. Jin and Y. Cheng, “ CFD simulation with detailed chemistry of steam reforming of Methane for hydrogen production in an integrated micro-reactor” , Int J
Hydrogen Energy , vol. 35, pp. 5383 - 5392, 2010.

[8] T. Boger, “ Monolithic catalysts for the chemical Industry”, Ind Eng Chem Res, vol.43 ,pp. 4602-4611, 2004.

[9] R.S. Benson and J .W. Ponton., " Process Miniaturisation-A Route to Total Environmental Acceptability”, Chem. Eng. Res. Des. ,vol. 71,pp. 160-168,1993.

[10] A.Y. Tonkovich, B. Yang , S.T. Perry, S.P. Fitzgerald, Y. Wang , " From seconds to milliseconds to microseconds through tailored microchannel reactor design of a steam Methanereformer”, Catal Today, vol.120 ,pp. 21-29, 2007.

[11] R. J. Bradley, L.C. Nathan, N.T. Diana, A.D. Robert, D.H. Jamelyn, Y. Wang , “ Engineered SMR catalysts based on hydrothermally stable, porous, ceramic supports for microchannel reactors” ,Catal Today,vol. 120 , pp. 54-62, 2007.

[12] A.K. Avci, D.L. Trimm, M. Karakaya, “ Microreactor catalytic combustion for chemicals processing”, Catal Today,vol.155 ,pp. $66-74,2010$.

[13] G. Arzamendi, P.M. Diéguez, M. Montes, J.A. Odriozola, E. Falabella, E. Sousa-Aguiar and L.M .Gandía, "Methane steam reforming in a microchannel reactor for GTL intensification: A computational fluid dynamics simulation study ", Chemical Engineering Journal , vol.168 ,pp. 168-173, 2009.

[14] A. Fazeli, M. Behnam, “ Hydrogen production in a zigzag and straight catalytic wall coated micro channel reactor by CFD modeling”, Int J Hydrogen Energy, vol.35 ,pp. 9496-9503, 2009..

[15] G. Arzamendi, P.M. Diéguez, M. Montes, M.A . Centeno, J.A. Odriozola, L.M . Gandía, "Integration of methanol steam reforming and combustion in a microchannel reactor for H2 production: A CFD simulation study ", Catalysis Today, vol.143, pp. 25-31,2009.

[16] S. Fukahori, H. Koga, T . Kitaoka, M. Nakamura, H. Wariis hi , “ Steam reforming behavior of methanol using paper-structured catalysts: experimental and computational fluid dynamic analysis”, Int J Hydrogen Energy, vol. 33, pp. 1661-70,2008.

[17] I.Uriz, G.Arzamendi, E.,López,J. Llorca, L.M. Gandía , “Computational fluid dynamics simulation of ethanol steam reforming in catalytic wall microchannels ", Chemical Engineering Journal, vol.167 ,pp. 536-544, 2011.

[18] L. Shi, D.J. Bayless and M.E. Prudich , “ A CFD model of autothermal reforming”, Int J Hydrogen Energy, vol.34 ,pp. 7666-7675, 2009.

[19] M. Hartmanna, L . Maierb, O. Deutschmann, “ Hydrogen production by catalytic partial oxidation of iso-octane at varying flow rate and fuel/oxygen ratio: From detailed kinetics to reactor behavior”, Applied CatalysisA:General , vol.391, pp. 144-152, 2011.

[20] M . Hartmann, L. Maier and H.D .Minh, “ Deutschmann O. Catalytic partial oxidation of iso-octane over rhodium catalysts: An experimental, modeling, and simulation study”, Combustion and Flame, vol.157, pp. 1771-1782,2010.

[21] K. Zygourakis and R. Aris, “ Multiple oxidation reactions and diffusion in the catalytic layer of monolith reactors”, Chem. Eng Sci ,vol.32, pp. 733-744,1983.

[22] Influence of the propene diffusion inside the catalytic layer", Chemical Engineering Science, vol.55,pp. 1707-1716,2000.

[23] M.J. Stutz, D. Poulikakos, “ Optimum washcoat thickness of a monolith reactor for syngas production by partial oxidation of Methane” ,Chemical Engineering Science ,vol.63 ,pp. 1761 1770,2008

[24] N. Mladenov, J. Koop, S. Tischer, O. Deutschmann "Modeling of transport and chemistry in channel flows of automotive catalytic converters ", Chem.Eng.Sci, vol.65, pp. 812-826, 2010. 
[25] Hoseini N, Msc thesis, Tarbiat Modares University: Tehran- Iran, 2010.

[26] J.P. Du Plessis, W.G. Gray, “ Pore-scale modeling of interstitial transport phenomena. In: Fluid Transport in Porous media”, Computational Mechanics Publication Southampton, pp.
61-104,1997.

[27] H.K. Plummer, R.J. Jr, R.H. Baird, A.A. Hammerle and Adamczyk JD, "Measurement of Automotive Catalyst Washcoat Loading Parameters by Microscopy Techniques”, Microscopy and Microanalysis, vol.5, pp. 267-281,1999. 